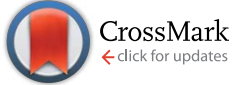

Cite this: RSC Adv., 2014, 4, 58426

\title{
A triple bond side-chained 2D-conjugated benzodithiophene based photovoltaic polymert
}

\author{
Shuguang Wen,,$^{\mathrm{b}}$ Xiao Yun,,$^{\mathrm{ab}}$ Weichao Chen, ${ }^{\mathrm{b}}$ Qian Liu, ${ }^{\mathrm{ab}}$ Dangqiang Zhu, ${ }^{\mathrm{b}}$ \\ Chuantao Gu, ${ }^{\text {b Mingliang Sun }}{ }^{* a}$ and Renqiang Yang*b
}

A series of triple bond side-chained benzodithiophene copolymers, derived from 4,8-bis(1-ethynyl-3,5bis(octyloxy)phenyl)-benzo[1,2-b:4,5- $\left.b^{\prime}\right]$ dithiophene, were synthesized by Stille coupling reactions. Several electron acceptors are introduced into the polymer backbone to tune the photo-electronic properties of the copolymers. The obtained copolymers are readily soluble in common organic solvents, such as toluene, THF and chloroform. The number average molecular weights of these polymers were determined by GPC using a polystyrene standard, ranging from 15400 to 28300 which are decent results for polymers with a rigid triple bond side chain. These polymers show high decomposition temperature $\left(403-419^{\circ} \mathrm{C}\right)$, narrow band gap (1.27-1.89 eV), and low-lying HOMO energy level ( -5.4 to $-5.6 \mathrm{eV}$ ). The best polymer solar cell (PSC) device based on the copolymer PBDTPA-TPD and PC ${ }_{61} \mathrm{BM}$ showed a power conversion efficiency (PCE) of $0.93 \%$ with a $V_{\text {oc }}=0.96 \mathrm{~V}, J_{\text {sc }}=1.9 \mathrm{~mA} \mathrm{~cm}^{-2}$, and $\mathrm{FF}=51 \%$, which is one of the highest $V_{\mathrm{oc}}$ values achieved by a benzodithiophene polymer.

Received 10th September 2014 Accepted 30th October 2014

DOI: 10.1039/c4ra10154e

www.rsc.org/advances two dimensional (2D) conjugated BDT, dialkyl-thiophene substituted BDT is synthesized, which to some extent reduces the HOMO energy level and extends the absorption spectrum of the polymer, compared to dialkoxy substituted BDT. ${ }^{\mathbf{1 3}-17}$ Besides the thiophene side chain of BDT, other conjugated side chains, such as thiophene $[3,2-b]$ thiophene, benzene etc. ${ }^{18}$ have also been tried to build a more efficient BDT photovoltaic polymer.

According to the sp hybrid in the hybrid orbital theory, the triple bond in the alkynyl group is a weak electron withdrawing group, meanwhile performs high rigidity which is good for intermolecular stacking. ${ }^{19}$ By introducing alkynyl group into BDT side chain, the HOMO energy level of polymer materials can be lowered, due to enhanced $\pi-\pi$ stacking. PCE of (tri-isopropyl-silyl) acetylene based BDT polymer have reached $5.76 \%,{ }^{20}$ but strong rigidity of triple bond leads to poor solubility of the polymer, which make it inconvenient for PSCs devices processing.

In this paper, to make more soluble alkynyl substituted BDT donor materials, we have designed and synthesized twodimension conjugated unit of dialkoxy-phenylacetylene substituted BDT, 4,8-bis(1-ethynyl-3,5-bis(octyloxy)phenyl)benzo[1,2-b:4,5- $\left.b^{\prime}\right]$ dithiophene (Scheme 1). Copolymerized with the acceptor TPD, DPP and TT (Scheme 2), three BDT based copolymers are obtained, and their optical properties, electrical properties and photovoltaic properties are studied.

${ }^{a}$ Institute of Material Science and Engineering, Ocean University of China, Qingdao 266100, People's Republic of China. E-mail: mlsun@ouc.edu.cn; Fax: +86-53266781927; Tel: +86-532-66781690

${ }^{b}$ CAS Key Laboratory of Bio-based Materials, Qingdao Institute of Bioenergy and Bioprocess Technology, Chinese Academy of Sciences, Qingdao 266101, People's Republic of China. E-mail: yangrq@qibebt.ac.cn; Fax: +86-532-80662778; Tel: +86532-80662700

$\dagger$ Electronic supplementary information (ESI) available. See DOI: 10.1039/c4ra10154e

\$ These authors contributed equally to this work.

\section{Experimental section}

\subsection{Materials}

Unless otherwise stated, all reagents and starting materials were used as commercially purchased without further 


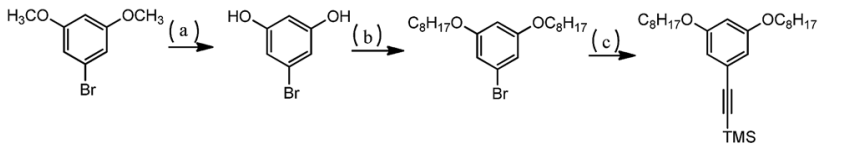

(M1) (M2) (M3)

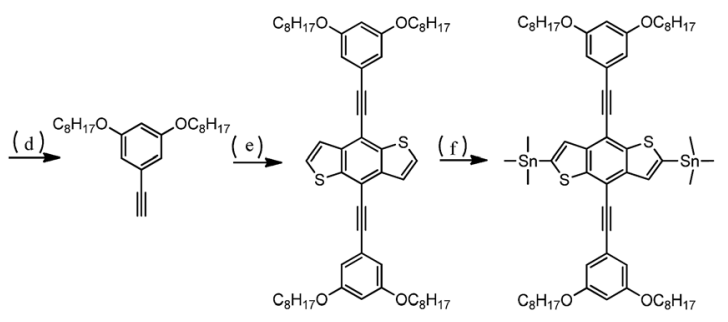

(M4)

(M5)

(M6)

Scheme 1 Synthetic routes of monomers. Reaction conditions: (a) $\mathrm{BBr}_{3}$, methylene chloride, $0^{\circ} \mathrm{C}$; (b) bromooctane, $\mathrm{K}_{2} \mathrm{CO}_{3}, \mathrm{DMF}, 60^{\circ} \mathrm{C}$; (c) ethynyl-trimethyl silicon, Cul, trans-dichlorobis(triphenyl-phosphine)palladium(॥), triethylamine, $80^{\circ} \mathrm{C}$; (d) $\mathrm{KOH}$, methylene chloride; (e) $n$-BuLi, THF, $0{ }^{\circ} \mathrm{C}, \mathrm{SnCl}_{2}$, reflux; (f) $n$-BuLi, $\mathrm{Me}_{3} \mathrm{SnCl}$, THF, $0{ }^{\circ} \mathrm{C}$.

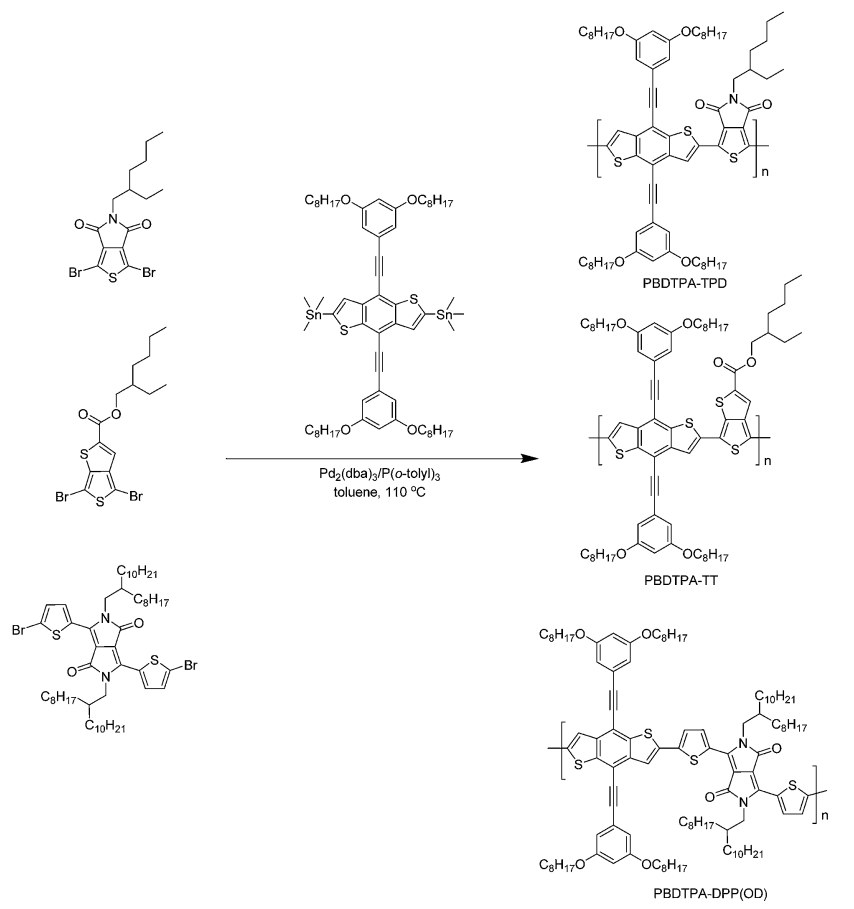

Scheme 2 Synthetic routes of polymers.

purification. The TPD, DPP and TT comonomers were purchased from Derthon Optoelectronic Materials Science Technology Co Ltd. Tetrahydrofuran (THF) and toluene were distilled from sodium with benzophenone as indicator and $N, N$-dimethylformamide (DMF) was distilled from $\mathrm{CaH}_{2}$ under argon atmosphere before use. All air and water sensitive reactions were performed under argon or nitrogen atmosphere.

\subsection{Materials characterization}

The nuclear magnetic resonance (NMR) spectra were recorded on a BrukerAdvanceIII $600(600 \mathrm{MHz})$ using $\mathrm{CDCl}_{3}$ as the solvent. UV-vis absorption spectra were measured with a Hitachi U-4100 spectrophotometer. The molecular weight and polydispersity were determined by gel permeation chromatography (GPC) analysis using an ELEOS System with polystyrenes as the reference standard and THF as an eluent. Thermogravimetric analysis (TGA) was performed on a TA-Q600 analyzer with a heating rate of $20{ }^{\circ} \mathrm{C} \mathrm{min}^{-1}$ under nitrogen. Electrochemical cyclic voltammetry (CV) measurements were conducted on an electrochemistry workstation (CHI660D) with a glassy carbon as working electrode, a platinum wire as counter electrode and an $\mathrm{Ag} / \mathrm{AgCl}$ as reference electrode under nitrogen in a solution of $\mathrm{Bu}_{4} \mathrm{NPF}_{6}(0.1 \mathrm{M})$.

\subsection{Device fabrication}

Photovoltaic devices were fabricated on pre-patterned indium tin oxide (ITO) coated glass substrates with a layered structure of ITO/PEDOT:PSS/donor:PC ${ }_{61} \mathrm{BM} / \mathrm{Ca}(10 \mathrm{~nm}) / \mathrm{Al}(100 \mathrm{~nm})$. The ITO coated glass substrates were cleaned in ultrasonic bath in acetone, toluene, methanol and isopropyl alcohol sequentially. After a twenty-minute oxygen plasma treatment, a thin layer of PEDOT:PSS (30 nm) was spin-coated onto the ITO anode and then dried at $120{ }^{\circ} \mathrm{C}$ for $20 \mathrm{~min}$. The photosensitive layer was prepared by spin-coating a blend solution of the polymers and $\mathrm{PC}_{61} \mathrm{BM}$ with a weight ratio of $1: 1.5$ in deoxygenated anhydrous $o$-dichlorobenzene on the ITO/PEDOT:PSS substrate and then annealed at $150{ }^{\circ} \mathrm{C}$ for $10 \mathrm{~min}$ in a glove box. $4 \%$ of DIO was added as processing additive to the blend solutions. The active layer thickness was around $90 \mathrm{~nm}$. Finally, Ca (10 nm) and aluminum (100 $\mathrm{nm}$ ) were thermally evaporated at a vacuum of $\sim 2 \times 10^{-4} \mathrm{~Pa}$ on top of active layer. The photovoltaic performance was measured under illumination at $100 \mathrm{~mW}$ $\mathrm{cm}^{-2}$ AM 1.5G irradiation using a Xe arc lamp in an argon atmosphere $\left(<0.1\right.$ ppm $\mathrm{H}_{2} \mathrm{O}$ and $\left.\mathrm{O}_{2}\right)$, and the current densityvoltage $(J-V)$ curves was obtained by Keithley 2400 . The external quantum efficiency (EQE) was obtained by a source meter, silicon photodiode and a computer-controlled light sourcemonochromator-lock-in system.

\subsection{Synthesis}

1-Bromo-3,5-di-hydroxyphenyl (M1). 3,5-Dimethoxybromobenzene $(10.0 \mathrm{~g}, 46.2 \mathrm{mmol})$ was dissolved in $100 \mathrm{ml}$ dry $\mathrm{CH}_{2} \mathrm{Cl}_{2}$. The solution of 3,5-dimethoxybromobenzene was cooled to $-78{ }^{\circ} \mathrm{C}$, and $1 \mathrm{M} \mathrm{CH}_{2} \mathrm{Cl}_{2}$ solution of $\mathrm{BBr}_{3}(100 \mathrm{ml}$, $100.0 \mathrm{mmol}$ ) was added slowly. Then, the solution was allowed to warm to ambient temperature overnight. The stirred solution was cooled to $0{ }^{\circ} \mathrm{C}$, and then quenched with $\mathrm{H}_{2} \mathrm{O}$. The aqueous phase was extracted with $\mathrm{Et}_{2} \mathrm{O}$. The combined organic layers were washed with $\mathrm{H}_{2} \mathrm{O}$, dried over $\mathrm{MgSO}_{4}$. Solvent was removed, and the resulting white solids were used for the next step reaction without further purification.

1-Bromo-3,5-bis(octyloxy)phenyl (M2). 1-Bromo-3,5-dihydroxyphenyl (3 g, $15.9 \mathrm{mmol})$ and anhydrous $\mathrm{K}_{2} \mathrm{CO}_{3}(16.21$ 
g) was diluted with $90 \mathrm{ml}$ of $N, N$-dimethylformamide, and the mixture was stirred at ambient temperature for $30 \mathrm{~min}$. After the addition of bromooctane $(12.4 \mathrm{~g}, 64.4 \mathrm{mmol})$, solution was heated at $60{ }^{\circ} \mathrm{C}$ overnight. The cooled reaction mixture was filtered through Celite, and concentrated to yield the crude product which was purified by column chromatography (hexane eluent) to obtain 1-bromo-3,5-bis(octyloxy)phenyl $4.4 \mathrm{~g}$ (10.5 mmol, 66.8\%). ${ }^{1} \mathrm{H} \mathrm{NMR}\left(\mathrm{CDCl}_{3}, 600 \mathrm{MHz}\right), \delta(\mathrm{ppm}): 6.63(\mathrm{~d}, 2 \mathrm{H})$, $6.36(\mathrm{t}, 1 \mathrm{H}), 3.89(\mathrm{t}, 4 \mathrm{H}), 1.75(\mathrm{~m}, 4 \mathrm{H}), 1.42(\mathrm{~m}, 4 \mathrm{H}), 1.29(\mathrm{~m}$, 16H), 0.89 (t, 6H) (Fig. S1 $\dagger$ ).

1-(Trimethylsilyl)ethynyl-3,5-bis(octyloxy)phenyl (M3). 1Bromo-3,5-bis(octyloxy)benzene (4.3 g, $10.5 \mathrm{mmol}$ ), copper iodide $(27.3 \mathrm{mg})$ and bis(triphenylphosphine)dichloridepalladium (336 mg) was dissolved in $42 \mathrm{ml}$ of dry triethylamine under nitrogen. After the mixture was heated to $50{ }^{\circ} \mathrm{C}$, trimethylsilylacetylene $(1.1 \mathrm{~g}, 11.4 \mathrm{mmol})$ was added. The solution was heated at $80{ }^{\circ} \mathrm{C}$ for $24 \mathrm{~h}$. The cooled reaction mixture was quenched with $2 \mathrm{M} \mathrm{HCl}$ solution, washed with $\mathrm{H}_{2} \mathrm{O}$, dried over $\mathrm{MgSO}_{4}$, and concentrated to yield crude product, which was purified by column chromatography (hexane eluent) to obtain $3.2 \mathrm{~g}$ of light yellow powder (7.3 mmol, 70\%). ${ }^{1} \mathrm{H} \mathrm{NMR}\left(\mathrm{CDCl}_{3}\right.$, $600 \mathrm{MHz}), \delta(\mathrm{ppm}): 6.62(\mathrm{~d}, 2 \mathrm{H}), 6.46(\mathrm{t}, 1 \mathrm{H}), 3.94(\mathrm{t}, 4 \mathrm{H}), 1.78$ $(\mathrm{m}, 4 \mathrm{H}), 1.46(\mathrm{~m}, 4 \mathrm{H}), 1.33(\mathrm{~m}, 16 \mathrm{H}), 0.92(\mathrm{t}, 6 \mathrm{H}), 0.27(\mathrm{~s}, 9 \mathrm{H})$ (Fig. S2†).

1-Ethynyl-3,5-bis(octyloxy)phenyl (M4). 1-(Trimethylsilyl) ethynyl-3,5-bis(octyloxy)benzene (3.2 g, $7.3 \mathrm{mmol}$ ) was dissolved in $35 \mathrm{ml}$ of dichloromethane, and $2.3 \mathrm{~g}$ of potassium hydroxide was dissolved in $35 \mathrm{ml}$ of methanol. These two solutions were mixed and stirred at ambient temperature for 3 h. The reactant was poured into water and extracted by dichloromethane. The organic layer was dried over anhydrous $\mathrm{MgSO}_{4}$. After removing solvent, the crude product was purified by column chromatography (hexane eluent) to obtain $2.4 \mathrm{~g}$ of light yellow powder (7.68 mmol, 99\%). ${ }^{1} \mathrm{H} \mathrm{NMR}\left(\mathrm{CDCl}_{3}, 600\right.$ $\mathrm{MHz}), \delta(\mathrm{ppm}): 6.65(\mathrm{~d}, 2 \mathrm{H}), 6.49(\mathrm{t}, 1 \mathrm{H}), 3.94(\mathrm{t}, 4 \mathrm{H}), 3.04(\mathrm{~s}, 1 \mathrm{H})$, $1.78(\mathrm{~m}, 4 \mathrm{H}), 1.46(\mathrm{~m}, 4 \mathrm{H}), 1.33(\mathrm{~m}, 16 \mathrm{H}), 0.92$ (t, 6H) (Fig. S3†).

4,8-Bis(1-ethynyl-3,5-bis(octyloxy)phenyl)-benzo[1,2-b:4,5- $\left.b^{\prime}\right]$ dithiophene (M5). 1-Ethynyl-3,5-bis(octyloxy)benzene (2 g, 6.4 $\mathrm{mmol}$ ) was dissolved in $70 \mathrm{ml}$ of dry THF under nitrogen. Solution was cooled to $0{ }^{\circ} \mathrm{C}$, and then $4 \mathrm{ml}$ of $n$-BuLi $(6.5 \mathrm{mmol}$, $1.6 \mathrm{M}$ ) was added dropwise. The mixture was stirred at $0{ }^{\circ} \mathrm{C}$ for $30 \mathrm{~min}$, then benzo[1,2- $\left.b: 4,5-b^{\prime}\right]$ dithiophene-4,8-dione $(0.67 \mathrm{~g}$, $3.1 \mathrm{mmol}$ ) was added. The stirred mixture was heated at reflux for $1 \mathrm{~h}$, then cooled to $0{ }^{\circ} \mathrm{C}$ again. $3.3 \mathrm{~g}$ of tin chloride dihydrate dissolved in $50 \mathrm{ml} 20 \% \mathrm{HCl}$ solution was added, and the reaction was heated at reflux for $2 \mathrm{~h}$. The cooled reaction mixture was extracted with ether. The organic layer was washed with $\mathrm{H}_{2} \mathrm{O}$ several times, dried over $\mathrm{MgSO}_{4}$, and concentrated to yield crude product, which was purified by column chromatography (hexane-dichloromethane $(8: 1, \mathrm{v} / \mathrm{v})$ eluent) to obtain $1.3 \mathrm{~g}$ of light yellow powder (1.47 mmol, 45\%). ${ }^{1} \mathrm{H} \mathrm{NMR}\left(\mathrm{CDCl}_{3}, 600\right.$ $\mathrm{MHz}), \delta(\mathrm{ppm}): 7.74$ (d, 2H), $7.62(\mathrm{~d}, 2 \mathrm{H}), 6.84(\mathrm{~d}, 4 \mathrm{H}), 6.55(\mathrm{t}$, $2 \mathrm{H}), 4.02(\mathrm{t}, 8 \mathrm{H}), 1.84(\mathrm{~m}, 8 \mathrm{H}), 1.51(\mathrm{~m}, 8 \mathrm{H}), 1.36(\mathrm{~m}, 32 \mathrm{H}), 0.93$ $(\mathrm{t}, 12 \mathrm{H})$ (Fig. S4†).

2,6-Bis(trimethyltin-4,8-bis(1-ethynyl-3,5-bis(octyloxy)phenyl)benzo[1,2- $\left.b: 4,5-b^{\prime}\right]$ dithiophene) (M6). 4,8-Bis(1-ethynyl-3,5bis(octyloxy)phenyl)-benzo[1,2- $\left.b: 4,5-b^{\prime}\right]$ bithiophene (BDTPA)
(0.6 g, $0.68 \mathrm{mmol}), N, N, N, N$-tetramethylethylenediamine (0.28 $\mathrm{ml}, 1.8 \mathrm{mmol}$ ) was dissolved in $30 \mathrm{ml}$ of dry THF under nitrogen. The mixture was cooled to $0{ }^{\circ} \mathrm{C}$, and $1.2 \mathrm{ml}$ of $n$-BuLi (1.8 mmol, $1.6 \mathrm{M})$ was added dropwise. After being stirred at $0{ }^{\circ} \mathrm{C}$ for $4 \mathrm{~h}, 2.2 \mathrm{ml}$ of $1 \mathrm{M}$ trimethyltin chloride was added slowly. The stirred solution was warm up to ambient temperature for overnight. After the reaction, the solution was poured into water and extracted by ether. The organic layer was dried over anhydrous $\mathrm{MgSO}_{4}$. After removing solvent under vacuum, the residue was recrystallized from isopropanol to obtain $0.67 \mathrm{~g}$ of product $(0.544 \mathrm{mmol}, 80 \%) .{ }^{1} \mathrm{H}$ NMR $\left(\mathrm{CDCl}_{3}, 600 \mathrm{MHz}\right), \delta$ (ppm): $7.76(\mathrm{t}, 2 \mathrm{H}), 6.86(\mathrm{~d}, 4 \mathrm{H}), 6.55(\mathrm{t}, 2 \mathrm{H}), 4.03(\mathrm{t}, 8 \mathrm{H}), 1.84$ $(\mathrm{m}, 8 \mathrm{H}), 1.51(\mathrm{~m}, 8 \mathrm{H}), 1.36(\mathrm{~m}, 32 \mathrm{H}), 0.93(\mathrm{t}, 12 \mathrm{H}), 0.52(\mathrm{t}, 18 \mathrm{H})$ (Fig. S5†). ${ }^{13} \mathrm{C} \mathrm{NMR}\left(\mathrm{CDCl}_{3}, 150 \mathrm{MHz}\right), \delta(\mathrm{ppm}): 160.1,144.7$, 143.6, 139.1, 130.9, 124.2, 110.2, 110.0, 102.9, 98.7, 85.6, 68.3, 31.8, 29.4, 29.2, 26.0, 22.7, 14.1, -8.2 (Fig. S6†). Anal. calcd for $\mathrm{C}_{64} \mathrm{H}_{94} \mathrm{O}_{4} \mathrm{~S}_{2} \mathrm{Sn}_{2}$ : C, 62.55; H, 7.71; S, 5.22. Found: C, 62.73; H, 7.62; S, 5.15. HRMS (APCI) $m / z$ : calcd $1229.4632[\mathrm{M}+1]^{+}$, found: 1229.4740.

PBDTPA-TPD. 2,6-Bis(trimethyltin)-4,8-bis(1-ethynyl-3,5bis(octyloxy)phenyl)-benzo[1,2- $\left.b: 4,5-b^{\prime}\right]$ dithiophene (184.4 mg, $0.15 \mathrm{mmol}$ ), 1,3-dibromo-5-(2-ethylhexyl)-thieno[3,4-c]pyrrole4,6-dione (TPD) (63.5 mg, $0.15 \mathrm{mmol})$, (o-tolyl)phosphine (7.3 $\mathrm{mg}, 16 \%)$ and tris(dibenzylideneacetone)dipalladium $(2.8 \mathrm{mg}, 2 \%)$ was dissolved in $5 \mathrm{ml}$ dry toluene under nitrogen. The mixture was heated to $70{ }^{\circ} \mathrm{C}$ for $4 \mathrm{~h}$. Then, the stirred solution was heated to $110{ }^{\circ} \mathrm{C}$ for $48 \mathrm{~h}$. After the reaction, the cooled mixture was dropped into methanol. The precipitate was collected and Soxhlet-extracted in sequence with methanol, hexane and chloroform. The product was dried under vacuum for 1 day to obtain the target polymer PBDTPA-TPD as a dark red solid. ${ }^{1} \mathrm{H} \mathrm{NMR}\left(\mathrm{CDCl}_{3}, 600 \mathrm{MHz}\right)$, $\delta(\mathrm{ppm}):$ 9.5-7.5 (m), 7.2-5.5 (m), 4.5-3.3 (m), 2.3-0.3 (m) (Fig. S7 $\dagger$ ). GPC (THF, polystyrene standard): $M_{\mathrm{n}}=23.9 \mathrm{kDa}$, $M_{\mathrm{w}}=57.7 \mathrm{kDa}, \mathrm{PDI}=2.41$.

PBDTPA-TT. 2,6-Bis(trimethyltin)-4,8-bis(1-ethynyl-3,5-bis(octyloxy)phenyl)-benzo[1,2- $\left.b: 4,5-b^{\prime}\right]$ dithiophene (122.9 mg, 0.1 mmol), 2-ethylhexyl-4,6-dibromo-thieno[3,4- $b]$ thiophene-2carboxylate (TT) (48.6 mg, $0.1 \mathrm{mmol})$, tris(o-tolyl)phosphine (4.9 mg, 16\%) and tris(dibenzylideneacetone)dipalladium (1.8 $\mathrm{mg}, 2 \%$ ) was dissolved in $5 \mathrm{ml}$ of dry toluene under nitrogen. The other procedures are just as PBDTPA-TPD polymer. Finally, the target polymer PBDTPA-TT is obtained as a dark solid. ${ }^{1} \mathrm{H}$ NMR $\left(\mathrm{CDCl}_{3}, 600 \mathrm{MHz}\right), \delta(\mathrm{ppm}):$ 8.5-7.5 (m), 7.2-6 (m), 4.5-3.2 (m), 2.2-0.3 (m) (Fig. S8 †). GPC (THF, polystyrene standard): $M_{\mathrm{n}}=15.4 \mathrm{kDa}, M_{\mathrm{w}}=81.2 \mathrm{kDa}, \mathrm{PDI}=5.25$.

PBDTPA-DPP (OD). 2,6-Bis(trimethyltin)-4,8-bis(1-ethynyl3,5-bis(octyloxy)phenyl)-benzo[1,2- $\left.b: 4,5-b^{\prime}\right]$ dithiophene (61.4 $\mathrm{mg}, 0.05 \mathrm{mmol}$ ), 3,6-bis(5-bromo-thiophen-2-yl)-2,5-bis(2-octyldodecyl)pyrrolo[3,4-c]pyrrole-1,4-(2H,5H)-dione (DPP(OH)) (50.9 $\mathrm{mg}, 0.05 \mathrm{mmol})$, tris(o-tolyl)phosphine $(2.4 \mathrm{mg}, 16 \%)$ and tris(dibenzylideneacetone)dipalladium $(0.9 \mathrm{mg}, 2 \%)$ was dissolved in $5 \mathrm{ml}$ dry toluene under nitrogen. The other procedures are just as PBDTPA-TPD polymer. Finally, the target polymer PBDTPA-DPP(OD) is obtained as a dark green solid. ${ }^{1} \mathrm{H}$ NMR $\left(\mathrm{CDCl}_{3}, 600 \mathrm{MHz}\right), \delta(\mathrm{ppm}): 9.0-8.5(\mathrm{~m}), 7.1-6.2(\mathrm{~m}), 4.0(\mathrm{~s}), 2.1-$ 
Table 1 Molecule weight and optical properties of the polymers ${ }^{a, b}$

\begin{tabular}{|c|c|c|c|c|c|c|c|}
\hline Polymer & $M_{\mathrm{n}}(\mathrm{k})$ & $M_{\mathrm{w}}(\mathrm{k})$ & PDI & $\lambda_{\max }-\mathrm{S}(\mathrm{nm})$ & $\lambda_{\max }-\mathrm{F}(\mathrm{nm})$ & $\varepsilon\left(\mathrm{cm}^{-1}\right)$ thin film & $E_{\mathrm{g}}^{\mathrm{opt}}(\mathrm{eV})$ \\
\hline PBDTPA-TPD & 23.9 & 57.7 & 2.41 & 587 & 613 & $4.1 \times 10^{4}$ & 1.89 \\
\hline PBDTPA-TT & 15.4 & 81.2 & 5.25 & 603 & 624 & $2.4 \times 10^{4}$ & 1.37 \\
\hline
\end{tabular}

${ }^{a} \lambda_{\max }-\mathrm{S}$ : absorption peak in solution; $\lambda_{\max }-\mathrm{F}$ : absorption peak in film. ${ }^{b} E_{\mathrm{g}}^{\mathrm{opt}}$ : optical band gap is calculated from $1240 / \lambda_{\text {onset }}$.

$1.2(\mathrm{~m})$ (Fig. S9†). GPC (THF, polystyrene standard): $M_{\mathrm{n}}=28.3$ $\mathrm{kDa}, M_{\mathrm{w}}=275.6 \mathrm{kDa}, \mathrm{PDI}=9.72$.

\section{Results and discussion}

\subsection{Synthesis and characterization}

The general synthetic routes toward the monomer and copolymers are outlined in Schemes 1 and 2 respectively. All the compounds are characterized by ${ }^{1} \mathrm{H}$ NMR spectra. They are in accordance with the literature ${ }^{21}$ for the precursors and show correctly the designed structure for polymers (see ESI Fig. S7S9†). The obtained copolymers are readily soluble in common organic solvents, such as toluene, THF, and chloroform. The number-average molecular weights of these polymers were determined by GPC using a polystyrene standard, ranging from 15400 to 28300 with a polydispersity index $\left(M_{\mathrm{w}} / M_{\mathrm{n}}\right)$ between 2.41 and 9.72. The molecular weights data is summarized in Table 1.

The thermal properties of the polymer were measured with a heating rate of $20^{\circ} \mathrm{C} \mathrm{m^{-1 }}$ under inert atmosphere. As shown in Fig. 1, the decomposition temperature $\left(T_{\mathrm{d}}\right)$ at $5 \%$ weight loss of PBDTPA-TPD, PBDTPA-TT and PBDTPA-DPP(OD) was $419.7{ }^{\circ} \mathrm{C}$, 403.7 ${ }^{\circ} \mathrm{C}$ and $401.7{ }^{\circ} \mathrm{C}$ respectively. The high decomposition temperature decreases the possibility of the deformation of the polymer film morphology and the degradation of the polymer active layer under applied electric fields in solar cell devices.

\subsection{Optical properties}

The absorption spectra of the polymers were measured both in chloroform solution and in thin films (Fig. 2, Table 1). Since the different electron acceptors of copolymers lead to various absorption spectral features, PBDTPA-TPD, PBDTPA-TT and

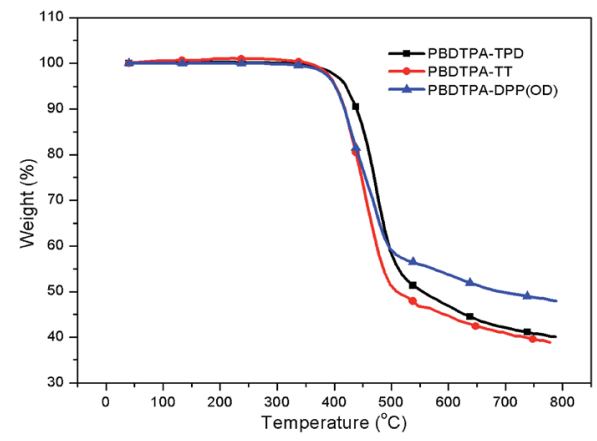

Fig. 1 TGA plots of the polymers with a heating rate of $20^{\circ} \mathrm{C} \mathrm{min}^{-1}$ under an inert atmosphere.
PBDTPA-DPP(OD) exhibit absorption peaks at $\sim 587,603$ and $683 \mathrm{~nm}$ respectively. Compared to the absorption in solution, the thin films show red-shifted UV-vis absorption spectrum, with absorption peaks at $\sim 613,624$ and $784 \mathrm{~nm}$, respectively. Especially for PBDTPA-DPP(OD), the absorption spectrum becomes broader and shows a $101 \mathrm{~nm}$ red-shifted in thin film, which can be attributed to the planar polymer chain structure and effective inter-chain $\pi-\pi$ stacking in the solid state. The introduction of alkynyl group enhances intermolecular interactions by extending the $2 \mathrm{D}$ conjugation of polymers. The absorption coefficients were tested in thin film and middle value $\left(<5 \times 10^{4} \mathrm{~cm}^{-1}\right)$ were obtained for all three polymers, which may cause limited photocurrent in solar cells. ${ }^{22}$

\subsection{Electrochemical characterization}

Cyclic voltammogram (CV) (Fig. 3) was performed to evaluate the HOMO and LUMO energy levels of all the polymers. HOMO

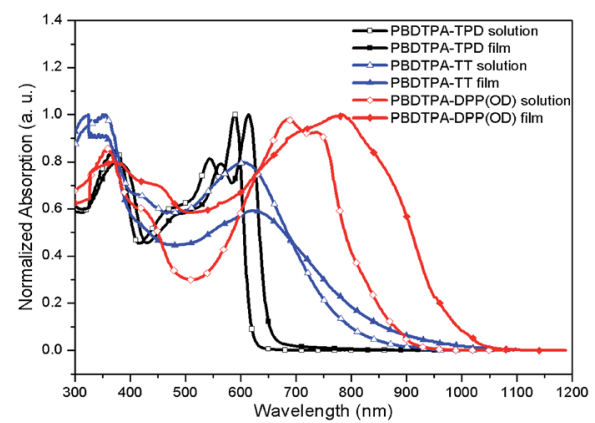

Fig. 2 Normalized absorption spectra of the polymers in chloroform solution and in thin film.

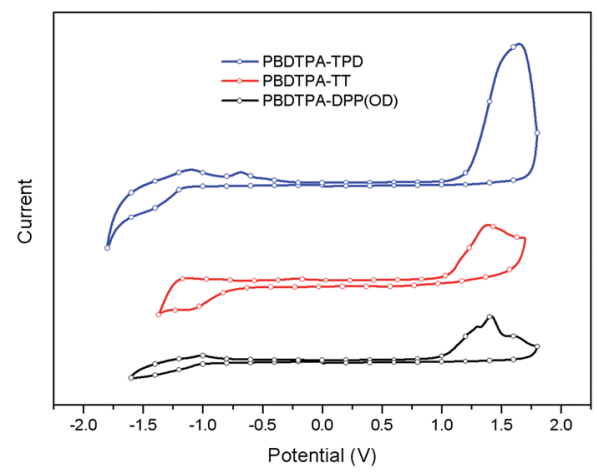

Fig. 3 Cyclic voltammogram of the polymers. 
Table 2 Electrochemical properties of the polymers

\begin{tabular}{llllll}
\hline Polymer & $E_{\text {ox }}(\mathrm{V})$ & $E_{\text {red }}(\mathrm{V})$ & HOMO $(\mathrm{eV})$ & LUMO $(\mathrm{eV})$ & LUMO $^{\text {opta }}(\mathrm{eV})$ \\
\hline PBDTPA-TPD & 1.24 & -1.17 & -5.65 & -3.24 & -3.76 \\
PBDTPA-TT & 1.05 & -0.85 & -5.44 & -3.57 & -4.07 \\
PBDTPA-DPP(OD) & 1.01 & -1.02 & -5.42 & -3.39 & -4.15
\end{tabular}

${ }^{a} \mathrm{LUMO}^{\mathrm{opt}}=\mathrm{HOMO}-E_{\mathrm{g}}^{\mathrm{opt}} \cdot{ }^{b} E_{\mathrm{g}}^{\mathrm{cv}}=\mathrm{LUMO}-$ HOMO.

and $E_{\mathrm{LUMO}}$ were estimated from the onset oxidation potential and reduction potential of the polymer film. ${ }^{23}$ The HOMO and LUMO levels are calculated according to the empirical formula $E_{\mathrm{HOMO}}=-\mathrm{e}\left(E_{\mathrm{ox}}^{\text {onset }}+4.4\right) \mathrm{eV}$ and $E_{\mathrm{LUMO}}=-\mathrm{e}\left(E_{\mathrm{red}}^{\text {onset }}+4.4\right) \mathrm{eV}$. The data are listed in Table 2. The polymers show deep HOMO level around -5.6 and $-5.4 \mathrm{eV}$, which may result in high open circuit voltage $\left(V_{\mathrm{oc}}\right)$ in OSC device. Meanwhile, the LUMO levels were calculated from optical band gap. The materials of PBDTPA-TT and PBDTPA-DPP(OD) exhibit low LUMO ${ }^{\text {opt }}$ value of below -4.0 $\mathrm{eV}$, which may lead to insufficient exciton dissociation at donor-acceptor interfaces. ${ }^{24}$

\subsection{Photovoltaic performance}

Polymer solar cells (PSCs) devices were fabricated with the resultant polymer as the donor and $\mathrm{PC}_{61} \mathrm{BM}$ as the acceptor to investigate the photovoltaic properties of the polymer. The device structure is ITO/PEDOT:PSS/polymer: $\mathrm{PC}_{61} \mathrm{BM} / \mathrm{Ca} / \mathrm{Al}$. To improve the photovoltaic performance of the device, 1,8diiodooctane (DIO) was used as the additive and the optimized D/A ratio of polymer: $\mathrm{PC}_{61} \mathrm{BM}$ was $1: 1.5$ (Fig. S10 $\dagger$ ). Fig. 4 shows the current density-voltage curves $(J-V)$ of the devices under the illumination of AM $1.5 \mathrm{G}\left(100 \mathrm{~mW} \mathrm{~cm}{ }^{-2}\right)$. The PBDTPA-TPD/PC ${ }_{61} \mathrm{BM}$ device exhibited the best PCE of $0.93 \%, V_{\mathrm{oc}}$ of $0.96 \mathrm{~V}$. Due to the low-lying HOMO energy level of PBDTPA-TPD $(-5.4 \mathrm{eV})$, the PSCs based on PBDTPA-TPD show nearly $1 \mathrm{~V}(0.96 \mathrm{~V}) V_{\mathrm{oc}}$ which is one of the highest $V_{\mathrm{oc}}$ value achieved by benzodithiophene polymer. For PBDTPA$\mathrm{DPP}(\mathrm{OD}) / \mathrm{PC}_{61} \mathrm{BM}$ based PSCs devices, the best result was obtained with a PCE $=0.39 \%$ and a $V_{\text {oc }}$ of $0.45 \mathrm{~V}$. PBDTPA-TT based device performances wasn't listed in Table 3, because it does not show photovoltaic response in the ITO/

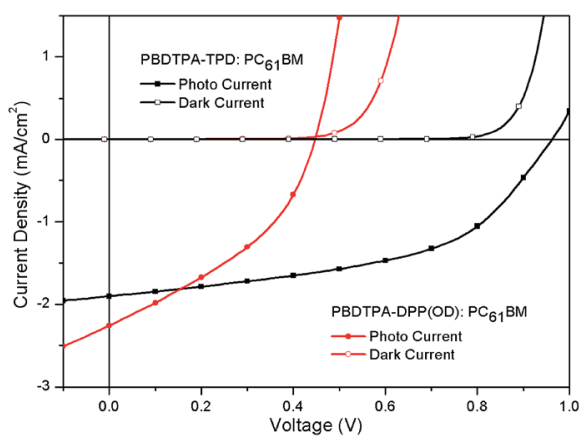

Fig. $4 J-V$ curves of the PSCs based on the blend of PBDTPA-TPD or PBDTPA-DPP(OD)/PC ${ }_{61} B M$ under the illumination of AM 1.5, $100 \mathrm{~mW}$ $\mathrm{cm}^{-2}$.
PEDOT:PSS/polymer: $\mathrm{PC}_{61} \mathrm{BM} / \mathrm{Ca} / \mathrm{Al}$ device structure. For polymers PBDTPA-DPP(OD) and PBDTPA-TT, the deep LUMO level $(<-4.0 \mathrm{eV})$ may be a detrimental factor for the low PCE value, because the LUMO-LUMO offset with $\mathrm{PC}_{61} \mathrm{BM}$ acceptor is less than $0.3 \mathrm{eV}$ and exciton dissociation could not be sufficiently efficient. Furthermore, low value of absorption coefficient would also reduce the PCE of OSC (Table 1). The dark $J-V$ curves were tested for polymers of PBDTPA-TPD and PBDTPA-DPP(OD) (Fig. 4). It shows good diode character.

The external quantum efficiency (EQE) spectra of the devices are shown in Fig. 5. EQE value of $<20 \%$ were obtained for polymers PBDTPA-TPD and PBDTPA-DPP(OD). The EQE spectrum of PBDTPA-DPP(OD) shows relatively low value beyond $500 \mathrm{~nm}$, while its maximum absorption in film is at about $784 \mathrm{~nm}$. This mismatch reflect insignificant contribution from the major absorption of PBDTPA-DPP(OD) to the photocurrent of solar cell. ${ }^{25}$ That is to say, the conversion of the low-energy excitons (from the polymer's absorption) to harvestable free charges is not efficient. This is most probably due to the poor dissociation efficiency of the low-energy excitons as the polymer-PC ${ }_{61} \mathrm{BM}$ LUMO energy difference is too small $(<0.3 \mathrm{eV}) .{ }^{26}$ This induces less-effective utilization of the absorption and low $J_{\mathrm{sc}}$ is obtained as a result.

Table 3 Solar cells devices performance of PBDTPA-TPD and PBDTPA-DPP(OD)

\begin{tabular}{lllll}
\hline Active layer & $V_{\mathrm{oc}}(\mathrm{V})$ & $J_{\mathrm{sc}}\left(\mathrm{mA} \mathrm{cm}^{-2}\right)$ & $\mathrm{FF}(\%)$ & PCE $(\%)$ \\
\hline PBDTPA-TPD/PC & & & & \\
PBD & 0.96 & 1.90 & 51 & 0.93 \\
PBDPA-DPP(OD)/PC $_{61} \mathrm{BM}$ & 0.45 & 2.26 & 39 & 0.39
\end{tabular}

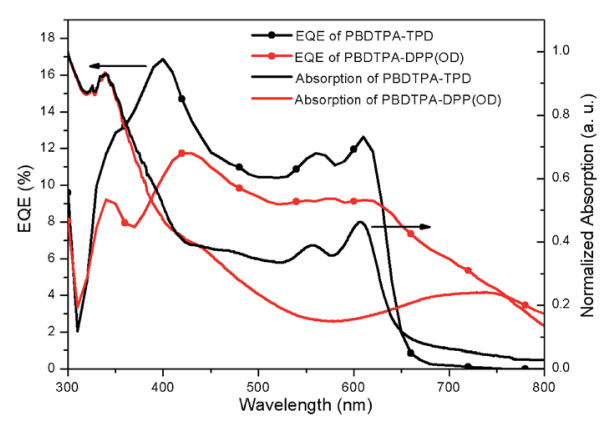

Fig. 5 EQE curves of the PSCs based on the blend of PBDTPA-TPD or PBDTPA-DPP(OD)/PC ${ }_{61} B M$ and optical absorptions for the corresponding polymer/PC ${ }_{61} \mathrm{BM}$ blend film. 


\section{Conclusions}

In summary, a series of triple bond side-chained benzodithiophene copolymer, derived from 4,8-bis(1-ethynyl-3,5-bis(octyloxy)phenyl)-benzo[1,2- $\left.b: 4,5-b^{\prime}\right]$ dithiophene, were synthesized. By introducing soluble bis(octyloxy)phenyl substituted triple band as side chain of DBT polymer, decent molecule weight $(15.4 \mathrm{k}$ to $28.3 \mathrm{k})$ is achieved for polymers with rigid triple band side chain. These polymers show high decomposition temperature and low-lying HOMO energy level. The best PSCs device based on the copolymer PBDTPA-TPD and PC $_{61}$ BM showed a nearly $1 \mathrm{~V}(0.96 \mathrm{~V}) V_{\text {oc }}$. Further work to make more efficiency triple bond side-chained benzodithiophene polymer is underway.

\section{Acknowledgements}

The authors are deeply grateful to the National Natural Science Foundation of China (Project no. 21274134, 21202181, 51173199 and 61405209), New Century Excellent Talents in University (NCET-11-0473), and Qingdao Municipal Science and Technology Program (13-1-4-200-jch) for financial support.

\section{References}

1 B. C. Thompson and J. M. Fréchet, Angew. Chem., Int. Ed., 2008, 47, 58.

2 J. W. Chen and Y. Cao, Acc. Chem. Res., 2009, 42, 1709.

3 G. Li, R. Zhu and Y. Yang, Nat. Photonics, 2012, 6, 153.

4 R. Duan, L. Ye, X. Guo, Y. Huang, P. Wang, S. Zhang, J. Zhang, L. Huo and J. Hou, Macromolecules, 2012, 45, 3032.

5 G. Dennler, M. C. Scharber and C. J. Brabec, Adv. Mater., 2009, 21, 1323.

6 P. M. Beaujuge and J. M. Freìchet, J. Am. Chem. Soc., 2011, 133, 20009.

7 H. Zhou, L. Yang and W. You, Macromolecules, 2012, 45, 607.

8 H. Pan, Y. Li, Y. Wu, P. Liu, B. S. Ong, S. Zhu and G. Xu, J. Am. Chem. Soc., 2007, 129, 4112.

9 L. Huo and J. Hou, Polym. Chem., 2011, 2, 2453.
10 J. Hou, M. H. Park, S. Zhang, Y. Yao, L. M. Chen, J. H. Li and Y. Yang, Macromolecules, 2008, 41, 6012.

11 S. H. Liao, Y. S. Cheng and S. A. Chen, Adv. Mater., 2013, 25, 4766.

12 D. Lee, E. Hubijar, G. J. D. Kalaw and J. P. Ferraris, Chem. Mater., 2012, 24, 2534.

13 J. Min, Z. G. Zhang, S. Y. Zhang and Y. F. Li, Chem. Mater., 2012, 24, 3247.

14 Y. Huang, X. Guo, F. Liu, L. Huo, Y. Chen, T. P. Russell, C. C. Han, Y. F. Li and J. H. Hou, Adv. Mater., 2012, 24, 3383.

15 L. Dou, W. H. Chang, J. Gao, C. C. Chen, J. B. You and Y. Yang, Adv. Mater., 2012, 25, 825.

16 J. Y. Yuan, Z. C. Zhai, H. L. Dong, J. Li, Z. Q. Jiang, Y. F. Li and W. L. Ma, Adv. Funct. Mater., 2012, 23, 885.

17 M. J. Zhang, Y. Gu, X. Guo, F. Liu, S. Q. Zhang, L. J. Huo, T. P. Russell and J. H. Hou, Adv. Mater., 2013, 25, 4944.

18 J. H. Kim, C. E. Song, B. S. Kim, I. N. Kang, W. S. Shin and D. H. Hwang, Chem. Mater., 2014, 26, 1234.

19 P. Sista, H. Nguyen, J. W. Murphy, J. Hao, D. K. Dei, K. Palaniappan, J. Servello, R. S. Kularatne, B. E. Gnade, B. Xue, P. C. Dastoor, M. C. Biewer and M. C. Stefan, Macromolecules, 2010, 43, 8063.

20 C. Bathula, S. E. Cho, S. Badgujar, S. J. Hong, I. N. Kang, S. J. Moon, J. Lee, S. Cho, H. K. Shim and S. K. Lee, J. Mater. Chem., 2012, 22, 22224.

21 H. G. Kim, S. B. Jo, C. Shim, J. Lee, J. Shin, E. C. Cho, S. G. Ihn, Y. S. Choi, Y. Kim and K. Cho, J. Mater. Chem., 2012, 22, 17709.

22 B. C. Thompson and J. M. J. Fréchet, Angew. Chem., Int. Ed., 2008, 47, 58.

23 Y. F. Li, Y. Cao, J. Gao, D. L. Wang, G. Yu and A. J. Heeger, Synth. Met., 1999, 99, 243.

24 Y. Li, B. Xu, H. Li, W. Cheng, L. Xue, F. Chen, H. Lu and W. Tian, J. Phys. Chem. C, 2011, 115, 2386.

25 M. Zhang, X. Guo, X. Wang, H. Wang and Y. Li, Chem. Mater., 2011, 23, 4264.

26 M. C. Scharber and N. S. Sariciftci, Prog. Polym. Sci., 2013, 38, 1929. 